\title{
Evaluation of plant sterol intake estimated with the Northern Sweden FFQ
}

\author{
Sofia Klingberg ${ }^{1, *}$, Anna Winkvist ${ }^{1}$, Göran Hallmans ${ }^{2}$ and Ingegerd Johansson ${ }^{3}$ \\ 'Department of Internal Medicine and Clinical Nutrition, Institution of Medicine, Sahlgrenska Academy at \\ University of Gothenburg, PO Box 459, SE-405 30 Göteborg, Sweden: ${ }^{2}$ Department of Public Health and \\ Clinical Medicine, Nutritional Research, Umeå University, Umeå, Sweden: ${ }^{3}$ Department of Odontology, \\ Umeå University, Umeå, Sweden
}

Submitted 22 September 2011: Final revision received 27 March 2012: Accepted 24 April 2012: First published online 29 June 2012

\begin{abstract}
Objective: To evaluate plant sterol intake estimated with the eighty-four-item Northern Sweden FFQ against repeated $24 \mathrm{~h}$ dietary recalls (24-HDR) as the reference method.

Design: Randomly recruited participants from the Västerbotten Intervention Programme (VIP) responded to an FFQ (FFQ1). Over the subsequent 12 months, ten repeated 24-HDR were carried out. After this, a second FFQ (FFQ2) was completed. Setting: Västerbotten county, northern Sweden.

Subjects: Ninety-six men and ninety-nine women.

Results: The Pearson correlation coefficient for absolute total plant sterol intake estimated with FFQ1 and 24-HDR was 0.58 and 0.55 for the men and women, respectively. Cross-classification of participants into quartiles of absolute plant sterol intake estimated with FFQ1 and 24-HDR showed that $90 \%$ of the men and $83 \%$ of the women were classified into the same or an adjacent quartile. For energy-adjusted plant sterol intake, $71 \%$ of the men and $74 \%$ of the women were classified into the same or an adjacent quartile. The agreement for crossclassification of participants into quartiles between FFQ1 and FFQ2 was good for both absolute and energy-adjusted plant sterol intake.

Conclusions: The FFQ is able to capture absolute plant sterol intake to the same extent as other nutrients, and to rank individuals according to both their absolute and energy-adjusted plant sterol intake. The reproducibility of the FFQ was good, suggesting that the method is reliable. This makes it possible to use plant sterol data from the FFQ in large-scale studies of the association between plant sterol intake and disease.
\end{abstract}

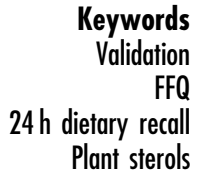

FFQ are frequently used in epidemiological studies because of the relatively low costs and limited efforts involved. Dietary intake estimated with FFQ is similar to dietary intake estimated with other dietary intake instruments subject to measurement errors, which can be both systematic and random. These measurement errors may lead to bias within individuals as well as between individuals ${ }^{(1,2)}$. Using dietary intake in estimates of dietdisease associations can lead to an attenuation of the association, since measurement errors tend to bias the estimate towards zero ${ }^{(3)}$.

The Northern Sweden FFQ is used in the Västerbotten Intervention Programme (VIP), which is part of the European Prospective Investigation into Cancer and Nutrition (EPIC), as well as in the Northern Sweden WHO Multinational Monitoring of Trends and Determinants in Cardiovascular Disease (MONICA) studies. The FFQ has been validated against ten repeated $24 \mathrm{~h}$ dietary recalls
(24-HDR) with regard to intake of foods, energy and macronutrients $^{(4)}$, vitamins and minerals ${ }^{(4,5)}$ and fatty acids $^{(6)}$. The correlation coefficients between the FFQ and 24-HDR for energy, fat and fibre were between 0.45 and $0 \cdot 61$, and the median correlation coefficient for energy, macronutrients and a range of micronutrients was $0 \cdot 50^{(4)}$. Thus, the estimated level of validity was similar to that of other FFQ used in prospective cohort studies.

Plant sterols are bioactive compounds occurring in all vegetable foods. The chemical structure of plant sterols is similar to that of cholesterol, and plant sterols play an important role in the structure and function of plant cell membranes ${ }^{(7)}$. Plant sterols inhibit cholesterol absorption in the gut by competing for space in micelles ${ }^{(8)}$. In addition, plant sterols are thought to regulate the proteins implicated in cholesterol metabolism in the enterocytes and hepatocytes, although this action is not yet fully understood ${ }^{(9)}$. Because of these effects on cholesterol, plant sterol intake 
reduces serum cholesterol levels. Dietary intake of naturally occurring plant sterols has generally been considered ineffective, since the amounts consumed are relatively low. The daily intake of naturally occurring plant sterols in Europe is approximately $300 \mathrm{mg}$ for men and varies from about 200 to about $300 \mathrm{mg}$ for women ${ }^{(10-13)}$. However, two clinical trials have shown that an intake of $300 \mathrm{mg} / \mathrm{d}$ reduces cholesterol absorption by $11 \%$ in a $3 \mathrm{~d} \mathrm{trial}^{(14)}$ and by $28 \%$ in a test meal trial $^{(15)}$. In addition, two large epidemiological studies have shown a significant inverse association between dietary intake of naturally occurring plant sterols and levels of serum cholesterol ${ }^{(11,16)}$. Therefore, it may be hypothesized that a high intake of naturally occurring plant sterols could reduce the risk of myocardial infarction.

The objective of the present study was to evaluate plant sterol intake estimated with the Northern Sweden FFQ, with repeated 24-HDR as the reference method.

\section{Materials and methods}

\section{The Västerbotten Intervention Programme}

The population-based VIP invites all inhabitants in Västerbotten county in northern Sweden to a health check-up at their primary health-care centre the year they turn 30, 40, 50 and 60 years of age. The programme has been running since 1985 and, on average, $60 \%$ of those invited participate ${ }^{(17)}$.

\section{Study population}

In 1992, a stratified random subsample of individuals participating in the VIP was asked to take part in a validation study ${ }^{(4)}$. A total of 246 individuals were invited, and 102 men and 101 women agreed to participate. This random sample was representative of the total study cohort with respect to smoking, BMI, total serum cholesterol and blood pressure, and the participants were equally distributed between the ages of 30, 40, 50 and 60 years $^{(4)}$. At the start of the validation study the participants completed an FFQ (FFQ1), followed by ten 24-HDR over the subsequent 12-month period. At the end of the study period a second FFQ (FFQ2) was completed. Eight participants were excluded: six did not complete all 24-HDR and two did not return FFQ1. In total, ninety-six men and ninety-nine women completed all ten 24-HDR and FFQ1, and all but two women also completed FFQ2. The Regional Ethical Review Board in Gothenburg, Sweden, has approved the analyses of the data presented here (registration number 622-05).

\section{FFQ (test method)}

The semi-quantitative FFQ with eighty-four questions ${ }^{(4)}$ was distributed immediately before the beginning of the 24-HDR period. The frequencies of consumption were reported on a scale of nine levels, ranging from never to four or more times daily. The questionnaire included eight questions on spreads and fats used for cooking; ten on dairy products; ten on bread and cereals; eleven on fruits, berries, vegetables, root vegetables and legumes; five on potatoes; six on cookies and sweets; twenty-one on meat, fish and mixed dishes; twelve on coffee, tea, alcoholic and other beverages; and one on salty snacks. The FFQ included four colour photographs with which the respondents indicated portion sizes of potatoes, rice and pasta; meat and fish; and vegetables. Energy and nutrient intakes were calculated using the food composition database (updated 1994) at the Swedish National Food Administration, Uppsala, Sweden, as previously described $^{(4)}$. A database of the analysed plant sterol content of more than 330 food items held at the Department of Clinical Nutrition at the University of Gothenburg, Sweden, was used to estimate plant sterol intake ${ }^{(18-20)}$. The plant sterol database comprises data for five individual plant sterols: the unsaturated plant sterols campesterol, stigmasterol and $\beta$-sitosterol, and the saturated plant stanols campestanol and $\beta$-sitostanol. The sum of the five individual plant sterols constitutes total plant sterol' and, unless specified otherwise, is referred to as 'plant sterol intake' in the present paper. The database and calculation of plant sterol intake from the FFQ have been described in detail elsewhere ${ }^{(11)}$.

\section{Repeated $24 \mathrm{~b}$ dietary recalls (reference method)}

The ten repeated 24-HDR were carried out by telephone during the 12-month period between FFQ1 and FFQ2 ${ }^{(4)}$. The ten 24-HDR were unannounced, equally dispersed throughout the period and covered all days of the week. The participants were interviewed in a standardized way and asked to report all consumed foods and drinks during the previous $24 \mathrm{~h}$. To help in estimating portion sizes, a booklet with full-size portion pictures was sent in advance to the participants ${ }^{(21,22)}$. Energy and nutrient intakes were calculated utilizing the database from the Swedish National Food Administration (updated 1994) as previously described $^{(4)}$. To estimate plant sterol intake, each food item consumed was allocated a plant sterol value based on analyses ${ }^{(18-20)}$ or recipe calculations of analysed ingredients.

\section{Statistical analyses and calculations}

All statistical calculations were performed separately for the men and women using the statistical software package PASW Statistics 18 for Windows (SPSS Inc.), except the weighted kappa statistics which were performed using the SAS statistical software package version $9 \cdot 2$ (SAS Institute Inc.). Intakes of plant sterols were normally distributed, and parametric methods were used. All statistical tests were two-sided and $P$ values below 0.05 were considered statistically significant.

To correct correlation coefficients for within-individual variation and between-individual variation an attenuation factor was calculated as $a_{\text {factor }}=\left\{\left[1+\left(C V_{\mathrm{w}} / C V_{\mathrm{b}}\right)_{x} / n_{x}\right]\right.$ $\left.\left[1+\left(C V_{\mathrm{w}} / C V_{\mathrm{b}}\right)_{y} / n_{y}\right]\right]^{0 \cdot 5}$, where $C V_{\mathrm{w}}$ is within-individual 
variation, $C V_{\mathrm{b}}$ is between-individual variation, $n$ is the number of repeated measurements, $x$ represents the FFQ and $y$ represents the $24-\mathrm{HDR}^{(2)}$.

Energy-adjusted intake of plant sterols was defined as intake per energy unit, i.e. $\mathrm{mg} / \mathrm{MJ}$.

Participants were classified into quartiles for absolute $(\mathrm{mg} / \mathrm{d})$ and energy-adjusted (mg/MJ) plant sterol intake by ranking the men and women separately according to their reported absolute plant sterol intake $(\mathrm{mg} / \mathrm{d})$ and energy-adjusted plant sterol intake $(\mathrm{mg} / \mathrm{MJ})$, respectively.

\section{Results}

Both the men and women had a mean age of 45 years and the proportions of 30-, 40-, 50- and 60-year-old participants were equal for both sexes. The men had a daily mean (minimum-maximum) energy intake of $9 \cdot 1(2 \cdot 7-21 \cdot 0) \mathrm{MJ}$ estimated with FFQ1, 8.7 $(4 \cdot 2-16 \cdot 2)$ MJ with FFQ2 and $9 \cdot 1(4 \cdot 6-16 \cdot 0) \mathrm{MJ}$ with 24-HDR. The corresponding estimated intakes for the women were $7 \cdot 1(4 \cdot 0-15 \cdot 3) \mathrm{MJ}$, $6 \cdot 9(3 \cdot 6-12 \cdot 2) \mathrm{MJ}$ and $6 \cdot 9(3 \cdot 1-12 \cdot 4) \mathrm{MJ}$, respectively.

The mean (95\% CI) intakes, Pearson correlation coefficients and calibration coefficients of absolute plant sterol intake (mg/d) estimated with FFQ1 and 24-HDR are reported separately for the men and women in Table 1. The corresponding data on energy-adjusted plant sterol intake $(\mathrm{mg} / \mathrm{MJ})$ are presented in Table 2.

The men had a mean (minimum-maximum) total plant sterol intake of 257 (71-561) $\mathrm{mg} / \mathrm{d}$ estimated with FFQ1 and 226 (68-496) mg/d estimated with 24-HDR. The women had an intake of 219 (107-446) mg/d and 197 (77-401) mg/d, respectively. The Pearson correlations between absolute intakes of individual plant sterols

Table 1 Absolute intake of plant sterols (mg/d) estimated with the first administration of the Northern Sweden FFQ (FFQ1) and ten repeated $24 \mathrm{~h}$ dietary recalls $(24-\mathrm{HDR})$ in ninety-six men and ninety-nine women participating in the Västerbotten validation study

\begin{tabular}{|c|c|c|c|c|c|c|c|c|c|c|c|c|}
\hline & \multirow[b]{2}{*}{ Gender } & \multicolumn{2}{|c|}{ FFQ1 } & \multicolumn{2}{|c|}{ 24-HDR } & \multicolumn{2}{|c|}{$\begin{array}{c}\text { Ratio } \\
\text { FFQ1:24-HDR* }\end{array}$} & \multicolumn{3}{|c|}{$\begin{array}{l}\text { Pearson correlation } \\
\text { coefficientt }\end{array}$} & \multicolumn{2}{|c|}{$\begin{array}{l}\text { Calibration } \\
\text { coefficient‡ }\end{array}$} \\
\hline & & Mean & $95 \% \mathrm{Cl}$ & Mean & $95 \% \mathrm{Cl}$ & Mean & $95 \% \mathrm{Cl}$ & Crude & $P$ value & De-attenuated & $\lambda$ value & $95 \% \mathrm{Cl}$ \\
\hline \multirow[t]{2}{*}{ Campesterol } & Men & 66 & 61,71 & 61 & 56,65 & $1 \cdot 16$ & $1 \cdot 07,1 \cdot 25$ & 0.57 & $<0.001$ & 0.68 & 0.50 & $0.35,0.65$ \\
\hline & Women & 52 & 48,56 & 49 & 46,53 & $1 \cdot 12$ & $1 \cdot 04,1 \cdot 20$ & 0.54 & $<0.001$ & 0.63 & 0.48 & $0.33,0.63$ \\
\hline \multirow[t]{2}{*}{ Campestanol } & Men & $6 \cdot 2$ & $5 \cdot 6,6 \cdot 8$ & $4 \cdot 7$ & $4 \cdot 3,5 \cdot 0$ & $1 \cdot 42$ & $1 \cdot 30,1 \cdot 54$ & 0.50 & $<0.001$ & 0.59 & $0 \cdot 33$ & $0.21,0.44$ \\
\hline & Women & $5 \cdot 1$ & $4 \cdot 6,5 \cdot 5$ & $3 \cdot 7$ & $3 \cdot 4,4 \cdot 0$ & $1 \cdot 49$ & $1 \cdot 30,1 \cdot 69$ & 0.43 & $<0.001$ & 0.50 & $0 \cdot 27$ & $0.15,0.38$ \\
\hline \multirow{2}{*}{ Stigmasterol } & Men & 13 & 12,14 & 12 & 11,13 & $1 \cdot 16$ & $1 \cdot 07,1 \cdot 26$ & 0.57 & $<0.001$ & 0.65 & 0.57 & $0.40,0.74$ \\
\hline & Women & 12 & 11,12 & 12 & 11,12 & $1 \cdot 09$ & $1 \cdot 01,1 \cdot 17$ & 0.47 & $<0.001$ & 0.55 & 0.54 & $0.34,0.75$ \\
\hline \multirow[t]{2}{*}{$\beta$-Sitosterol } & Men & 162 & 150,174 & 141 & 132,151 & $1 \cdot 21$ & $1 \cdot 11,1 \cdot 30$ & 0.57 & $<0.001$ & 0.67 & 0.46 & $0.32,0.59$ \\
\hline & Women & 142 & 133,152 & 126 & 118,134 & $1 \cdot 18$ & $1 \cdot 10,1 \cdot 26$ & 0.55 & $<0.001$ & 0.64 & 0.44 & $0.31,0.58$ \\
\hline \multirow[t]{2}{*}{$\beta$-Sitostanol } & Men & $9 \cdot 9$ & $9 \cdot 1,10 \cdot 8$ & $7 \cdot 8$ & $7 \cdot 2,8 \cdot 4$ & $1 \cdot 34$ & $1 \cdot 23,1.45$ & 0.50 & $<0.001$ & 0.59 & 0.34 & $0.22,0.45$ \\
\hline & Women & $8 \cdot 1$ & $7 \cdot 5,8 \cdot 7$ & $6 \cdot 1$ & $5 \cdot 7,6 \cdot 5$ & $1 \cdot 41$ & $1 \cdot 28,1 \cdot 54$ & 0.46 & $<0.001$ & 0.54 & $0 \cdot 31$ & $0.19,0.43$ \\
\hline \multirow[t]{2}{*}{ Total sterol } & Men & 257 & 238,276 & 226 & 211,242 & $1 \cdot 19$ & $1 \cdot 11,1 \cdot 28$ & 0.58 & $<0.001$ & 0.68 & 0.47 & $0.33,0.61$ \\
\hline & Women & 219 & 204,233 & 197 & 185,209 & $1 \cdot 17$ & $1 \cdot 09,1 \cdot 24$ & 0.55 & $<0.001$ & 0.64 & 0.46 & $0.32,0.60$ \\
\hline
\end{tabular}

*Mean $(95 \% \mathrm{Cl})$ of individual ratios between intakes estimated with FFQ1 and 24-HDR.

tThe Pearson correlation coefficient between plant sterol intakes estimated with FFQ1 and 24-HDR, crude coefficients and after de-attenuation.

$\ddagger$ The calibration coefficient, with $95 \% \mathrm{Cl}$ corresponding to the slope of the regression of the plant sterol intake estimated with $24-\mathrm{HDR} v$. the intake estimated with FFQ1.

Table 2 Energy-adjusted plant sterol intake (mg/MJ) estimated with the first administration of the Northern Sweden FFQ (FFQ1) and ten repeated $24 \mathrm{~h}$ dietary recalls $(24-\mathrm{HDR})$ in ninety-six men and ninety-nine women participating in the Västerbotten validation study

\begin{tabular}{|c|c|c|c|c|c|c|c|c|c|c|c|c|}
\hline & \multirow[b]{2}{*}{ Gender } & \multicolumn{2}{|c|}{ FFQ1 } & \multicolumn{2}{|c|}{ 24-HDR } & \multicolumn{2}{|c|}{$\begin{array}{c}\text { Ratio } \\
\text { FFQ1:24-HDR* }\end{array}$} & \multicolumn{3}{|c|}{$\begin{array}{c}\text { Pearson correlation } \\
\text { coefficientt }\end{array}$} & \multicolumn{2}{|c|}{$\begin{array}{l}\text { Calibration } \\
\text { coefficientł }\end{array}$} \\
\hline & & Mean & $95 \% \mathrm{Cl}$ & Mean & $95 \% \mathrm{Cl}$ & Mean & $95 \% \mathrm{Cl}$ & Crude & $P$ value & De-attenuated & $\lambda$ value & $95 \% \mathrm{Cl}$ \\
\hline \multirow[t]{2}{*}{ Campesterol } & Men & $7 \cdot 3$ & $7 \cdot 0,7 \cdot 6$ & $6 \cdot 6$ & $6 \cdot 3,6 \cdot 9$ & $1 \cdot 14$ & $1 \cdot 08,1 \cdot 20$ & 0.23 & $<0.05$ & 0.29 & 0.21 & $0.03,0.39$ \\
\hline & Women & $7 \cdot 3$ & $6 \cdot 9,7 \cdot 6$ & $7 \cdot 2$ & $6 \cdot 9,7 \cdot 4$ & $1 \cdot 04$ & $0.98,1.09$ & $0 \cdot 31$ & $<0.01$ & 0.38 & 0.23 & $0.09,0.38$ \\
\hline \multirow[t]{2}{*}{ Campestanol } & Men & 0.69 & $0.63,0.74$ & 0.53 & $0.49,0.56$ & $1 \cdot 36$ & $1 \cdot 27,1 \cdot 46$ & 0.40 & $<0.001$ & 0.48 & 0.28 & $0.15,0.41$ \\
\hline & Women & 0.71 & $0.66,0.75$ & 0.56 & $0.53,0.59$ & $1 \cdot 32$ & $1 \cdot 22,1 \cdot 42$ & 0.31 & $<0.01$ & 0.39 & 0.20 & $0.08,0.32$ \\
\hline \multirow[t]{2}{*}{ Stigmasterol } & Men & $1 \cdot 4$ & $1 \cdot 3,1 \cdot 5$ & $1 \cdot 3$ & $1 \cdot 2,1 \cdot 4$ & $1 \cdot 15$ & $1 \cdot 08,1 \cdot 22$ & 0.33 & $<0.01$ & 0.39 & 0.38 & $0 \cdot 16,0.61$ \\
\hline & Women & $1 \cdot 6$ & $1 \cdot 6,1 \cdot 7$ & $1 \cdot 7$ & $1 \cdot 6,1 \cdot 8$ & $1 \cdot 01$ & $0.96,1.06$ & 0.48 & $<0.001$ & 0.57 & 0.54 & $0.34,0.74$ \\
\hline \multirow{2}{*}{$\beta$-Sitosterol } & Men & 18 & 17,19 & 16 & 15,16 & $1 \cdot 18$ & $1 \cdot 12,1 \cdot 23$ & $0 \cdot 30$ & $<0.01$ & 0.36 & 0.27 & $0 \cdot 10,0.44$ \\
\hline & Women & 20 & 19,21 & 19 & 18,19 & $1 \cdot 08$ & $1 \cdot 04,1 \cdot 12$ & 0.53 & $<0.001$ & 0.63 & 0.46 & $0.32,0.61$ \\
\hline \multirow{2}{*}{$\beta$-Sitostanol } & Men & $1 \cdot 1$ & $1 \cdot 0,1 \cdot 2$ & 0.87 & $0.82,0.92$ & $1 \cdot 29$ & $1 \cdot 21,1 \cdot 37$ & $0 \cdot 36$ & $<0.001$ & 0.42 & 0.26 & $0 \cdot 12,0.40$ \\
\hline & Women & $1 \cdot 1$ & $1 \cdot 1,1 \cdot 2$ & 0.91 & $0.87,0.95$ & $1 \cdot 27$ & $1 \cdot 20,1 \cdot 34$ & 0.27 & $<0.01$ & 0.33 & 0.18 & $0.05,0.31$ \\
\hline \multirow[t]{2}{*}{ Total sterol } & Men & 28 & 27,29 & 25 & 24,26 & $1 \cdot 17$ & $1 \cdot 11,1 \cdot 23$ & $0 \cdot 28$ & $<0.01$ & 0.34 & 0.24 & $0.07,0.42$ \\
\hline & Women & 31 & 30,32 & 29 & 28,30 & $1 \cdot 07$ & $1 \cdot 03,1 \cdot 11$ & 0.46 & $<0.001$ & 0.56 & 0.39 & $0.24,0.54$ \\
\hline
\end{tabular}

*Mean $(95 \% \mathrm{Cl})$ of individual ratios between intakes estimated with FFQ1 and 24-HDR.

tThe Pearson correlation coefficient between energy-adjusted plant sterol intakes estimated with FFQ1 and 24-HDR, crude coefficients and after de-attenuation. $\ddagger$ The calibration coefficient, with $95 \% \mathrm{Cl}$ corresponding to the slope of the regression of energy-adjusted plant sterol intake estimated with $24-\mathrm{HDR} v$. the energyadjusted plant sterol intake estimated with FFQ1. 
Table 3 Reproducibility for absolute plant sterol intake $(\mathrm{mg} / \mathrm{d})$ and energy-adjusted plant sterol intake $(\mathrm{mg} / \mathrm{MJ})$ estimated with the first and second administration of the Northern Sweden FFQ (FFQ1 and FFQ2) at a 12-month interval, expressed as the ratio between FFQ1 and FFQ2, and the Pearson correlation coefficients in ninety-six men and ninety-seven women participating in the Västerbotten validation study

\begin{tabular}{|c|c|c|c|c|c|c|c|c|c|}
\hline & \multirow[b]{3}{*}{ Gender } & \multicolumn{4}{|c|}{ Plant sterol intake $(\mathrm{mg} / \mathrm{d})$} & \multicolumn{4}{|c|}{ Energy-adjusted plant sterol intake (mg/MJ) } \\
\hline & & \multicolumn{2}{|c|}{ Ratio FFQ1:FFQ2* } & \multirow{2}{*}{$\begin{array}{l}\text { Pearson correlation } \\
\text { coefficient } t\end{array}$} & \multirow[b]{2}{*}{$P$ value } & \multicolumn{2}{|c|}{ Ratio FFQ1:FFQ2* } & \multirow{2}{*}{$\begin{array}{l}\text { Pearson correlation } \\
\text { coefficientt }\end{array}$} & \multirow[b]{2}{*}{$P$ value } \\
\hline & & Mean & $95 \% \mathrm{Cl}$ & & & Mean & $95 \% \mathrm{Cl}$ & & \\
\hline \multirow[t]{2}{*}{ Campesterol } & Men & $1 \cdot 11$ & $1 \cdot 04,1 \cdot 19$ & 0.59 & $<0.001$ & 1.05 & $1 \cdot 00,1 \cdot 10$ & 0.50 & $<0.001$ \\
\hline & Women & 1.07 & $1 \cdot 01,1 \cdot 13$ & 0.66 & $<0.001$ & $1 \cdot 02$ & $0.99,1.06$ & 0.62 & $<0.001$ \\
\hline \multirow[t]{2}{*}{ Campestanol } & Men & $1 \cdot 13$ & $1 \cdot 03,1 \cdot 23$ & 0.69 & $<0.001$ & $1 \cdot 06$ & $0.99,1 \cdot 13$ & $0 \cdot 71$ & $<0.001$ \\
\hline & Women & $1 \cdot 12$ & $1 \cdot 03,1 \cdot 22$ & 0.53 & $<0.001$ & $1 \cdot 07$ & $1 \cdot 00,1 \cdot 14$ & 0.47 & $<0.001$ \\
\hline \multirow[t]{2}{*}{ Stigmasterol } & Men & 1.08 & $1 \cdot 03,1 \cdot 14$ & 0.79 & $<0.001$ & $1 \cdot 03$ & $1 \cdot 00,1 \cdot 06$ & 0.73 & $<0.001$ \\
\hline & Women & $1 \cdot 06$ & $1 \cdot 01,1 \cdot 11$ & $0 \cdot 71$ & $<0.001$ & $1 \cdot 02$ & $0.98,1.05$ & 0.72 & $<0.001$ \\
\hline \multirow[t]{2}{*}{$\beta$-Sitosterol } & Men & $1 \cdot 09$ & $1 \cdot 03,1 \cdot 15$ & $0 \cdot 67$ & $<0.001$ & $1 \cdot 03$ & $0.99,1.06$ & $0 \cdot 64$ & $<0.001$ \\
\hline & Women & $1 \cdot 06$ & $1 \cdot 01,1 \cdot 11$ & 0.64 & $<0.001$ & $1 \cdot 01$ & $0.98,1.04$ & 0.68 & $<0.001$ \\
\hline \multirow[t]{2}{*}{$\beta$-Sitostanol } & Men & $1 \cdot 11$ & $1 \cdot 03,1 \cdot 19$ & 0.66 & $<0.001$ & $1 \cdot 04$ & $0.99,1.09$ & 0.69 & $<0.001$ \\
\hline & Women & 1.09 & $1 \cdot 02,1 \cdot 17$ & 0.56 & $<0.001$ & $1 \cdot 05$ & $0.99,1 \cdot 10$ & 0.49 & $<0.001$ \\
\hline \multirow[t]{2}{*}{ Total sterol } & Men & $1 \cdot 09$ & $1 \cdot 03,1 \cdot 16$ & 0.66 & $<0.001$ & $1 \cdot 03$ & $1 \cdot 00,1 \cdot 07$ & $0 \cdot 61$ & $<0.001$ \\
\hline & Women & 1.06 & $1 \cdot 01,1 \cdot 11$ & 0.65 & $<0.001$ & $1 \cdot 01$ & $0.98,1.04$ & 0.66 & $<0.001$ \\
\hline
\end{tabular}

*Mean $(95 \% \mathrm{Cl})$ of individual ratios between intakes estimated with FFQ1 and FFQ2.

†The Pearson correlation coefficient between the plant sterol intakes estimated with FFQ1 and FFQ2.

estimated with FFQ1 and 24-HDR showed crude correlation coefficients between 0.50 and 0.58 for the men and 0.43 and 0.55 for the women (all $P<0.001$ ), while de-attenuated correlation coefficients were between 0.59 and 0.68 for the men and between 0.50 and 0.64 for the women, respectively. Linear regression of total plant sterol intake from 24-HDR $v$. FFQ1 showed a calibration factor of between 0.33 and 0.57 for the men and between $0 \cdot 27$ and 0.54 for the women.

Mean (minimum-maximum) energy-adjusted plant sterol intake was 28 (15-48) mg/MJ estimated with FFQ1 for the men and 25 (9-48) mg/MJ estimated with 24-HDR. For the women, energy-adjusted plant sterol intake was 31 (18-45) $\mathrm{mg} / \mathrm{MJ}$ and 29 (12-57) $\mathrm{mg} / \mathrm{MJ}$, respectively. The correlation coefficients between the intakes estimated by FFQ1 and 24-HDR ranged from 0.23 to 0.40 for the men and 0.27 to 0.53 for the women (all $P<0.05$ ). After de-attenuation, correlation coefficients ranged between $0 \cdot 29$ and 0.48 for the men and between 0.33 and 0.63 for the women. The calibration coefficients from linear regression of energy-adjusted plant sterol intake from 24-HDR $v$. FFQ1 were between $0 \cdot 21$ and $0 \cdot 38$ for the men and between $0 \cdot 18$ and 0.54 for the women.

The Pearson correlation coefficients for absolute plant sterol intake and energy-adjusted plant sterol intake estimated with FFQ1 were 0.46 for the men and 0.56 for the women, and 0.48 and 0.63 estimated with 24-HDR for the men and women, respectively (all $P<0 \cdot 001$ ).

The reproducibility of the FFQ with regard to absolute plant sterol intake $(\mathrm{mg} / \mathrm{d})$ and energy-adjusted plant sterol intake (mg/MJ) is shown in Table 3. The mean intake ratios for absolute plant sterol intake $(\mathrm{mg} / \mathrm{d})$ ranged between 1.08 and 1.13 for the men, and between 1.06 and 1.12 for the women. The corresponding figures for energy-adjusted plant sterol intake $(\mathrm{mg} / \mathrm{MJ})$ were between 1.03 and 1.06 for the men, and between 1.01 and 1.07 for the women.
The Pearson correlation coefficients for absolute plant sterol intake $(\mathrm{mg} / \mathrm{d})$ ranged from 0.59 to 0.79 for the men, and from 0.53 to 0.71 for the women (all $P<0.001$ ). The correlation coefficients for energy-adjusted plant sterol intake $(\mathrm{mg} / \mathrm{MJ})$ ranged from 0.50 to 0.73 for the men, and from $0 \cdot 47$ to 0.72 for the women (all $P<0 \cdot 001$ ).

The Bland-Altman plots (Fig. 1(a) to (d)) exhibit the difference between plant sterol intakes estimated with 24-HDR and FFQ1 plotted against the mean intake from the two methods. The plots indicate generally low mean differences and little systematic bias between the two methods.

Cross-classification of participants in quartiles of plant sterol intake estimated with 24-HDR $v$. FFQ1 and with FFQ1 $v$. FFQ2 is shown in Table 4. Cross-classification of absolute plant sterol intake quartiles estimated with the FFQ1 and 24-HDR revealed that $90 \%$ of the men and $83 \%$ of the women were classified into the same or an adjacent quartile, while $1 \%$ of both the men and women were grossly misclassified. For energy-adjusted plant sterol intake quartiles, $71 \%$ of the men and $74 \%$ of the women were classified into the same or an adjacent quartile. Severe misclassification was observed for $6 \%$ of the men and $4 \%$ of the women. Weighted kappa values for absolute plant sterol intake were over $0 \cdot 4$ for both men and women, while the values for energy-adjusted plant sterol intake were 0.17 for men and 0.25 for women. Cross-classification of absolute plant sterol intake quartiles estimated with FFQ1 and FFQ2 showed that $85 \%$ of the men and $95 \%$ of the women were classified into the same or an adjacent quartile, and that $1 \%$ of the men and none of the women were severely misclassified. Eighty-eight per cent of the men and $90 \%$ of the women were classified into the same or an adjacent quartile of energy-adjusted plant sterol intake $(\mathrm{mg} / \mathrm{MJ})$, and $2 \%$ of the men and $1 \%$ of the women were grossly misclassified. Weighted kappa values 

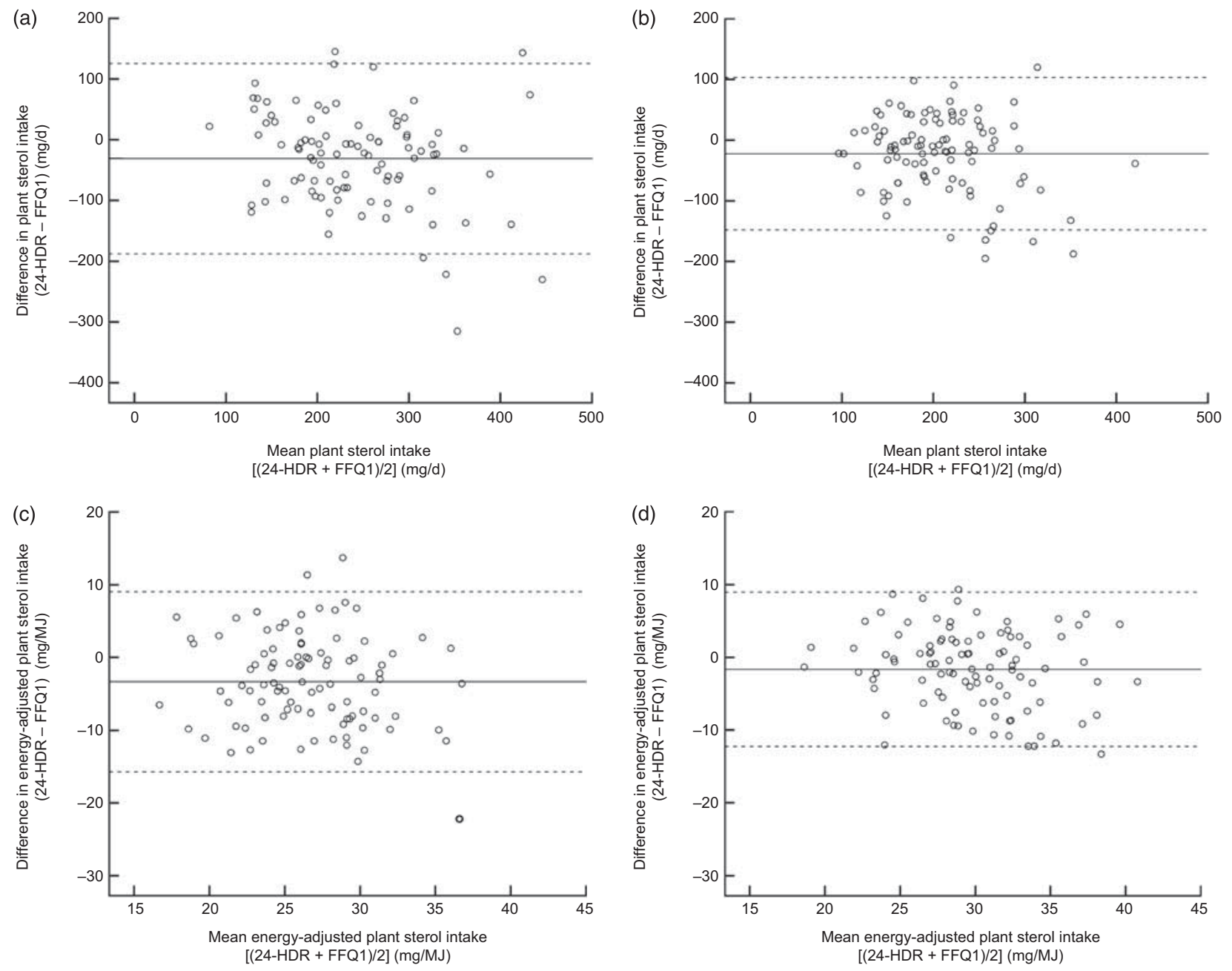

Fig. 1 Bland-Altman plots for (a) absolute total plant sterol intake in ninety-six men, (b) absolute total plant sterol intake in ninetynine women, (c) energy-adjusted total plant sterol intake in ninety-six men and (d) energy-adjusted total plant sterol intake in ninetynine women, all participating in the Västerbotten validation study. Differences in intakes estimated with the ten repeated $24 \mathrm{~h}$ dietary recalls (24-HDR) and the first administration of the Northern Sweden FFQ (FFQ1) are plotted against the mean intakes estimated with the two methods ( - , mean difference; - -.-, 95\% limits of agreement, i.e. mean difference $\pm 1.96 \mathrm{SD}$ of the difference between the two methods)

were about 0.5 for both absolute and energy-adjusted plant sterol intake for both men and women.

\section{Discussion}

In the present study we investigated the agreement between two dietary assessment methods, namely the Northern Sweden FFQ and ten repeated 24-HDR, with respect to absolute plant sterol intake $(\mathrm{mg} / \mathrm{d})$, energyadjusted plant sterol intake (mg/MJ) and the ability to rank individuals according to their plant sterol intake. Previous publications from this diet database have examined the agreement between these two methods, focusing on the intakes of foods, energy, macronutrients and a selection of micronutrients ${ }^{(4)}$, fatty acids ${ }^{(6)}$, folate and other $\mathrm{B}$ vitamins ${ }^{(5)}$. These previous studies have concluded that the validity of the Northern Sweden FFQ is similar to that of other FFQ used in large-scale studies.

The difficulty of dietary assessments in free-living populations is that all methods depend on individuals' subjective information on their food intake. Hence, these methods are subject to measurement errors of different kinds, which can be both random and systematic ${ }^{(1)}$. The development of biomarkers of nutrient intake is promising as it enables objective validation of dietary assessment methods ${ }^{(23)}$. Unfortunately, when it comes to plant sterols no biomarker for free-living individuals exists and probably never will, since very little of the plant sterols are absorbed in the intestine and consequently most are excreted with faeces. Additionally, plant sterols are found in a wide range of foods and with a large variation in each food group, making it impossible to use substitute biomarkers like those for fruit and vegetables (e.g. vitamin C 
and carotenoids in plasma) or fat (e.g. fatty acids in erythrocyte membranes). Therefore, studies such as the present one are important, i.e. comparisons of two dietary methods where one is presumed to be more accurate, but where the true intake remains uncertain.

The absolute intake of plant sterols estimated with FFQ1 was higher than that estimated with repeated 24-HDR: $19 \%$ higher in the men and $17 \%$ higher in the women. The individual plant stanols (campestanol and $\beta$-sitostanol) were overestimated with the FFQ more than the other plant sterols (campesterol, stigmasterol and $\beta$-sitosterol). Campestanol was $42 \%$ higher for the men in the FFQ and $49 \%$ higher for the women. For $\beta$-sitostanol the figures were $34 \%$ and $41 \%$ higher for men and women, respectively. The higher estimation of absolute plant sterol intake by the FFQ could be explained by the fact that the reported intake of plant sterol-containing foods such as bread, cereals, potatoes/rice/pasta, fruits and vegetables was higher in the FFQ than in the 24-HDR ${ }^{(4)}$. The plant stanols had a higher degree of overestimation by the FFQ than the plant sterols, despite the much lower intake, which could be a result of systematic misreporting. Plant stanols are almost only found in cereals and to a higher extent in wholegrain cereals. One possible explanation could be that the intake of wholegrain bread is overestimated in the FFQ, leading to an overestimation of plant stanol intake. Post hoc analyses support this explanation since consumption frequencies from the FFQ showed almost the same consumption of wholegrain bread and white bread, while data from the 24-HDR showed that wholegrain bread contributed only $25 \%$ of the consumed bread. The correlation coefficients between FFQ1 and the 24-HDR for absolute intakes of the individual plant sterols and total plant sterols were between 0.50 and 0.58 for the men, and between 0.43 and 0.55 for the women, and thus are comparable to those for other nutrients studied within this cohort ${ }^{(4-6)}$. As seen for most other nutrients, the correlation coefficients declined when energy-adjusted plant sterol intake was studied instead. This may be because the energy adjustment was made by dividing the plant sterol intake by the energy intake, and this quotient is dependent on two values that may differ between the two methods. Likewise, the calibration coefficient - showing how well the FFQ can predict the 'true value', i.e. the mean of ten $24-\mathrm{HDR}$ - was higher when absolute intakes were studied than when energy-adjusted intakes were studied.

Cross-classification of absolute plant sterol intake quartiles showed good agreement between the two methods, and very few individuals were grossly misclassified. Here too, cross-classification based on energy-adjusted plant sterol intake showed a slightly lower level of agreement, although more than $70 \%$ of the men and women were still classified into the same or an adjacent quartile. This suggests that the FFQ is able to rank individuals with acceptable accuracy according to both their absolute plant sterol intake and their energy-adjusted plant sterol intake. 
The agreement for cross-classification of FFQ1 and FFQ2 for both absolute plant sterol intake and energy-adjusted plant sterol intake was high, which suggests that the FFQ method is reliable. Intake ratios based on absolute intake revealed slightly higher reported intakes from FFQ1 than from FFQ2, perhaps suggesting an effect of exhaustion or a more pronounced under-reporting due to the repeated 24-HDR preceding the second FFQ. Another possible explanation is that the true intake has decreased. This effect was not seen, however, for energy-adjusted plant sterol intake.

Both the absolute intake of plant sterols ${ }^{(10,12,13,24)}$ and the energy-adjusted plant sterol intake ${ }^{(10,13)}$ in Sweden are slightly lower than those reported from other European countries. One explanation could be differences in dietary assessment methods. For example, the Swedish FFQ used in the present study consists of eighty-four questions compared with 150 questions in the Dutch study ${ }^{(12)}$ and 130 questions in the UK study ${ }^{(10)}$; hence, fewer questions could be a reason for the lower estimation of absolute plant sterol intake in Sweden. However, the energyadjusted plant sterol intake was also lower, indicating a true difference in plant sterol intake between Sweden and the Netherlands as well as the UK.

The random and systematic measurement errors inherent to all dietary assessment methods make nutrient intake data uncertain and a consequence could be that relationships between nutrients and health-related states and diseases remain undetected. A further challenge facing studies investigating the association between plant sterol intake and the risk of future illness is that the dispersion of dietary intakes of plant sterols is narrow: about $75 \%$ of both the men and women in our study had an intake between 150 and $350 \mathrm{mg} / \mathrm{d}$. This may make it difficult to find and show statistical associations between intake and the risk of disease. Here, larger research collaborations like EPIC are important as they represent populations with widely different dietary patterns.

\section{Conclusions}

The evaluation has demonstrated that the Northern Sweden FFQ is able to capture absolute plant sterol intake to the same extent as macronutrients and micronutrients. The FFQ is also able to rank individuals according to both their absolute plant sterol intake and their energy-adjusted plant sterol intake. Furthermore, investigation of the reproducibility showed that the agreement between FFQ1 and FFQ2 was good, suggesting that the method is reliable. This makes it possible to use plant sterol intake data from the FFQ in large-scale studies of the association between plant sterol intake and disease.

\section{Acknowledgements}

This work was funded by FORMAS, the Swedish Research Council for Environment, Agricultural Sciences and Spatial
Planning (grant 22·2/2003-0655); VR, the Swedish Research Council (grants K2005-27VX-15218-02B and K2006-27X20061-01-3); and the Swedish Nutrition Foundation. The plant sterol analyses were funded by a grant from the Swedish Government under the LUA agreement and the Swedish Cancer Foundation. The Västerbotten Intervention Programme (VIP) was funded by the Swedish Cancer Society, the Europe Against Cancer Programme and Västerbotten County Council. The development and maintenance of the dietary database is funded by grants from the Swedish Council for Working Life and Social Research and the Swedish Research Council. None of the authors have personal or financial conflict of interest. The authors' responsibilities were as follows. G.H. was the principal investigator in the VIP study; I.J. and A.W. were responsible for the dietary data of the VIP study; I.J. and S.K. prepared the plant sterol data set in the VIP cohort; S.K. was the principal investigator in the present study and wrote the paper with contributions from co-authors. Each author has seen and approved the content of the submitted manuscript. The authors acknowledge Lars Ellegård for insightful comments on the manuscript.

\section{References}

1. Kipnis V, Midthune D, Freedman L et al. (2002) Bias in dietary-report instruments and its implications for nutritional epidemiology. Public Health Nutr 5, 915-923.

2. Willett W (1998) Nutritional Epidemiology, Monographs in Epidemiology and Biostatistics, 2nd ed. New York, Oxford: Oxford University Press.

3. Kipnis V, Freedman LS, Brown CC et al. (1997) Effect of measurement error on energy-adjustment models in nutritional epidemiology. Am J Epidemiol 146, 842-855.

4. Johansson I, Hallmans G, Wikman A et al. (2002) Validation and calibration of food-frequency questionnaire measurements in the Northern Sweden Health and Disease cohort. Public Health Nutr 5, 487-496.

5. Johansson I, Van Guelpen B, Hultdin J et al. (2010) Validity of food frequency questionnaire estimated intakes of folate and other $\mathrm{B}$ vitamins in a region without folic acid fortification. Eur J Clin Nutr 64, 905-913.

6. Wennberg M, Vessby B \& Johansson I (2009) Evaluation of relative intake of fatty acids according to the Northern Sweden FFQ with fatty acid levels in erythrocyte membranes as biomarkers. Public Health Nutr 12, 1477-1484.

7. Piironen V, Lindsay DG, Miettinen TA et al. (2000) Plant sterols: biosynthesis, biological function and their importance to human nutrition. J Sci Food Agric 80, 939-966.

8. Plat J \& Mensink RP (2005) Plant stanol and sterol esters in the control of blood cholesterol levels: mechanism and safety aspects. Am J Cardiol 96, 15D-22D.

9. Calpe-Berdiel L, Escola-Gil JC \& Blanco-Vaca F (2009) New insights into the molecular actions of plant sterols and stanols in cholesterol metabolism. Atherosclerosis 203, 18-31.

10. Klingberg S, Andersson H, Mulligan A et al. (2008) Food sources of plant sterols in the EPIC Norfolk population. Eur J Clin Nutr 62, 695-703.

11. Klingberg S, Ellegård L, Johansson I et al. (2008) Inverse relation between dietary intake of naturally occurring plant sterols and serum cholesterol in northern Sweden. Am J Clin Nutr 87, 993-1001.

12. Normen AL, Brants HA, Voorrips LE et al. (2001) Plant sterol intakes and colorectal cancer risk in the Netherlands 
Cohort Study on Diet and Cancer. Am J Clin Nutr 74, 141-148.

13. Valsta LM, Lemstrom A, Ovaskainen ML et al. (2004) Estimation of plant sterol and cholesterol intake in Finland: quality of new values and their effect on intake. Br J Nutr 92, 671-678.

14. Ellegård L, Andersson H \& Bosaeus I (2005) Rapeseed oil, olive oil, plant sterols, and cholesterol metabolism: an ileostomy study. Eur J Clin Nutr 59, 1374-1378.

15. Ostlund Jr RE, Racette SB, Okeke A et al. (2002) Phytosterols that are naturally present in commercial corn oil significantly reduce cholesterol absorption in humans. Am J Clin Nutr 75, 1000-1004.

16. Andersson SW, Skinner J, Ellegård L et al. (2004) Intake of dietary plant sterols is inversely related to serum cholesterol concentration in men and women in the EPIC Norfolk population: a cross-sectional study. Eur J Clin Nutr 58, 1378-1385.

17. Weinehall L, Hallgren CG, Westman G et al. (1998) Reduction of selection bias in primary prevention of cardiovascular disease through involvement of primary health care. Scand J Prim Health Care 16, 171-176.
18. Normén L, Bryngelsson S, Johnsson M et al. (2002) The phytosterol content of some cereal foods commonly consumed in Sweden and in the Netherlands. I Food Compost Anal 15, 693-704.

19. Normen L, Ellegård L, Brants $\mathrm{H}$ et al. (2007) A phytosterol database: fatty foods consumed in Sweden and the Netherlands. J Food Compost Anal 20, 193-201.

20. Normen L, Johnsson M, Andersson H et al. (1999) Plant sterols in vegetables and fruits commonly consumed in Sweden. Eur J Nutr 38, 84-89.

21. Bergström L (1979) Illustrations of food items. Vår föda $\mathbf{3 1}$, 401-403.

22. Håglin L, Hagman U \& Nilsson M (1995) Evaluation of the meal model 'matmallen'. A means of estimating consumed amounts of food. Scand J Nutr 39, 79-83.

23. Jenab M, Slimani N, Bictash M et al. (2009) Biomarkers in nutritional epidemiology: applications, needs and new horizons. Hum Genet 125, 507-525.

24. Escurriol V, Mari-Dell'Olmo M, Rohlfs I et al. (2009) Plant sterol intake and education level in the Spanish EPIC cohort. Nutrition 25, 769-773. 